\title{
Transmission of bacterial virulence factors, a real and current threat to aquaculture production, a diagnostic challenge
}

\begin{abstract}
This short publication intends to present some basic information about the new bacterial disease called Acute hepatopancreas necrosis disease, which strongly affects the shrimp culture in Asia and America, causing high mortality rates. This condition is caused currently by at least strains of Vibrio parahaemolyticus, $V$. harveyi, V. owensii and $V$. campbellii. The geographic range of the epidemic is presented. Finally, it is explained why the participation of a binary toxin encoded by an extrachromosomal plasmid, results in traditional bacteriological methods having limited application in the diagnosis of the disease. Currently diagnosis of AHPND are based on molecular test (PCR) in combination whit histopathological techniques.
\end{abstract}

Keywords: bacterial disease, shrimp, plasmid, diagnosis, binary toxin, Vibrio strains
Volume 6 Issue 6 - 2018

\begin{abstract}
Alexander Varela
Aquaculture Diagnosis and Health Department, SRY Laboratory, Mexico

Correspondence: Alexander Varela, Aquaculture Diagnosis and Health Department, SRY Laboratory, Sonora, Mexico, Email alexander.varela@gmail.com
\end{abstract}

Received: April 29, 2018 | Published: December 03, 2018

\section{Introduction}

Globally, shrimp aquaculture production has been recurrently suffering the presence of various infectious diseases, which have caused great economic losses, affecting the stability of the industry, ${ }^{1-4}$ in this phenomenon, the bacterial etiology are currently one of the most important threats. ${ }^{5}$ The existence of specific virulence factors in bacterial species, has proven to be a fact in many species. The different bacterial strains can be more or less virulent than others and a lot of times, these differences are influenced by the presence or absence of genetic virulence factors contained into extrachromosomal plasmids. ${ }^{6}$ This fact hinders development and application in control and surveillance programs, as in the case of AHPND.

During recent years, cultured shrimp production is strongly affected for a new bacterial disease, which is caused by different strains of Vibrio, has spread since 2009. This pathology was named Acute hepatopancreatic necrosis disease (AHPND), his first reports were issued in China, then spread to Viet Nam in the year 2010, Malaysia in 2011, Thailand during the 2012,5,7,8 and Philippines. This emergent disease was recently included on chapter 2.2.1 of the Manual of Diagnostic Tests for Aquatic Animals, of the World Animal Health Organization (O.I.E), for your obligatory case report, and are one of two bacterial agents present on that list for crustaceans, other agents are virus or fungus.

Mortalities due of AHPND occur within 30-35 days, and as early as 10 days, of stocking shrimp ponds with postlarvae or juveniles, sometimes, these outbreaks can be occurring as late as 46-96 days after pond-stocking, with mortalities close to $100 \%$ of shrimp affected. AHPND was later detected in America's shrimp farms, strongly affected the shrimp production in Mexico during 2013, Central America and recently in Ecuador., ${ }^{5,10-17}$ And currently it is expected to continue its spread. The virulence of this bacterial strains, lies in the ability to synthesized a binary toxin (PirA and PirB), codified from a extrachromosomal plasmid of $69 \mathrm{~kb}$, called pVA1, this plasmids have a GC content of $45.9 \%$. $^{7,18,19}$

The gene sequence of one of this toxins of this plasmid, to PirB codifying, has a higher homology to the gene sequence for a toxin in other bacterial specie, the Photorhabdus luminescens, pathogenic for some type of insect larval stages. ${ }^{18}$ That plasmid pVA1 which as initially detected only in a Vibrio parahaemolyticus strain, $, 5,12,20$ however subsequent studies have demonstrated the presence of this same plasmid in other species of the genus Vibrio, currently confirmed on $V$. campbellii, $V$. harveyi and $V$. owensii strain, show the same AHPND pathogenic capability. ${ }^{10,21,22}$ Surprisingly, another bacterial strain that does not belong to the genus Vibrio, a Gram positive specie, Micrococcus luteus, was isolated from shrimp farms in Mexico in 2006 and was analyzed by nested PCR to confirm the presence of binary toxin genes. The isolates showed the presence of these genes, and these findings were confirmed by sequencing. Isolated from Mexico, however, has not yet been linked to the pathology or infection of shrimp. ${ }^{23}$

We are then faced with a relevant problem, it is not of a single bacterial species, already they have been detected other strains, belonging to other species, with the pathogenic capability to generate AHPND, additionally, not all strains of the species mentioned have this capacity, only Vibrio strains carriers of the toxigenic plasmid. Therefore, given that the pathogenic capacity of this agent is directly related to the presence of the plasmid, its standard bacteriological detection does not apply. Isolation of bacteria in specific agar, such as the TCBS, or Cromagar is not enough, but that it must demonstrate the presence of the plasmid and the genes encoding for the binary toxin. For the same reason, the biochemical identification tests are very limited and of low applicability. ${ }^{24}$

In response, we must rely on alternate diagnostic techniques, such as the clinical signs of animals affected, that clinical signal are used for only presumptive diagnoses, and should be supported his confirmation in the histopathology observations, ${ }^{13,25,26}$ in order to demonstrate the lesions characteristic of this disease. These lesions consist of massive detachment of the epithelial cells of the hepatopancreas, generated by the action of the binary toxin, which is released by the bacteria present in large quantity in the stomach of the shrimp; these toxins enter to the hepatopancreas and severely injured him. By this reason initially there is no bacterial presence in 
hepatopancreas, but if important lesions and absence of inflammatory response from sick animals. In the final stage of the infection, the hepatopancreas is invaded by the pathogenic bacteria, linked to a large number of opportunistic pathogenic or saprophytic bacteria., $5,13,25,26$

In addition, by requiring a high sensitivity and specificity confirmation, trials usually include molecular techniques, such as PCR in its different forms, with the use of primers developed to detect to the plasmid sequence in the regions that encode the binary toxins. ${ }^{17}$ Therefore, perform traditional bacteriology in hepatopancreas or stomachs, will indicate us that bacteria are present and their quantity, but do not allow establishing the presence or absence of plasmid or they toxins. Traditional bacteriology analysis techniques could be used, but only like a tool for cross control, to perform screenings of the quantities and types of bacteria present, indicating us sudden variations in the microbiome of the animals or pond environment. Currently, according to O. I. E standards in their aquatic manual, a case of AHPND is considered to be confirmed only if two or more of the following criteria are present:

a. Presence of histopathology lesions consistent with AHPND description.

b. Detection of Pir toxin gen in the pVA1 plasmid in Vibrio by PCR techniques and sequence analysis.

c. Positive results by bioassay (with the characteristic histological lesions and detection of AHPND by PCR and sequencing).

The AHPND will continue dispersing, and generating species of toxins will continue to grow, by transmission between strains of that plasmid, either by conjugation or transformation. It is imperative to develop reliable and rapid diagnostic techniques. The subtle genomic differences among different species and strains, as well as the constant flow of genetic information between them, using different routes, such as transformation, induction, transposition and bacterial, bacteriophages are increasingly complex a diagnosis. The use of more powerful techniques such as PCR has become a tool for everyday use, and in the case of the AHPND also histopathological verification. This requires a constant updating of techniques and methods. The AHPND outbreaks detection, monitoring, treatment and pathogen exclusion programs based on biosecurity protocols, need to develop more rapid, economic and sensitive tools and techniques. Finally, on this line, it is interesting those systems of detection of the toxin, due to its protein nature not have developed yet, using ELISA systems or similar tools, they can be an interesting and practical option for shrimp farmers, official authorities and researchers.

\section{Acknowledgments}

None.

\section{Conflicts of interest}

Author declares that there is no conflicts of interest.

\section{References}

1. McGladdery SE, East I, Subasinghe RP. Asia diagnostic guide to aquatic animal diseases. FAO Fisheries Technical Paper No. 402, Supplement 2. Rome, ITA: Network of Aquaculture Centers in Asia-Pacific (NACA) and FAO; $2001.37 \mathrm{p}$.

2. Burge EJ, Madigan DJ, Burnett LE, et al. Lysozyme gene expression by hemocytes of Pacific white shrimp, Litopenaeus vannamei, after injection with Vibrio. Fish Shellfish Immunol. 2007;22(4):327-339.

3. Decamp O, Moriarty DJ, Levens P. Probiotics for shrimp larviculture: review of field data from Asia and Latin America. Aquacult Res. 2008;39(4):334-338.

4. Varela A, Peña N. Hepatopancreatitis necrotizante asociada al Fenómeno del Niño, en cultivos de camarones del Golfo de Nicoya. Repertorio Científico. 2015;18(1):29-34.

5. Lightner DV, Redman R, Pantoja CR, et al. Documentation of an emerging disease (early mortality syndrome) in SE Asia \& Mexico. Tucson, AZ, USA: The University of Arizona; 2013. 53 p.

6. Youn-Lim J, Yoon JW, Hovde1 CJ. A Brief Overview of Escherichia coli O157:H7 and Its Plasmid O157. J Microbiol Biotechnol. 2010;20(1):514

7. Acute hepatopancreatic necrosis disease. $7^{\text {th }}$ ed. Manual of diagnostic tests for aquatic animals manual; 2016. $12 \mathrm{p}$.

8. Sriurairatana S, Boonyawiwat V, Gangnonngiw W, et al. White feces syndrome of shrimp arises from transformation, sloughing and aggregation of hepatopancreatic microvilli into vermiform bodies superficially resembling gregarines. PLoS ONE. 2014;9(6):e99170.

9. de la Peña LD, Cabillon NA, Catedral DD, et al. Acute hepatopancreatic necrosis disease (AHPND) outbreaks in Penaeus vannamei and $P$. monodon cultured in the Phillipines. Dis Aquat Organ. 2015;116(3):251254.

10. Ahn YS, Piamsomboon P, Tang KTF, et al. Complete Genome Sequence of Acute Hepatopancreatic Necrosis Disease- Causing Vibrio campbellii LA16-V1, Isolated from Penaeus vannamei Cultured in a Latin American Country. Genome Announc. 2017;5(37):e01011-e01017.

11. Han JE, Tang K, Lightner DV. Genotyping of virulence plasmid from Vibrio parahaemolyticus isolates causing acute hepatopancreatic necrosis disease in shrimp. Dis Aquat Organ. 2015;115(3):245-251.

12. Nunan L, Lightner DV, Pantoja CR, et al. Detection of acute hepatopancreatic necrosis disease (AHPND) in Mexico. Dis Aquat Organ. 2014;111(1):81-86.

13. Pantoja C, Lightner DV. EMS/AHPND description of the disease in Asia and America. In: Morales V, \& Cuéllar-Anjel J, editors. Pathology and Immunology of penaeid shrimp. Technical guide 2nd ed. El Salvador: OIRSA; 2014. 172-177 p.

14. Restrepo L, Bayot B, Betancourt I, et al. Draft genome sequence of pathogenic bacteria Vibrio parahaemolyticus strain Ba94C2, associated with acute hepatopancreatic necrosis disease isolate from South America. Genomics Data. 2016;9:143-144.

15. Saavedra-Olivos KY, Peralta-Ortiz T, Ordinola-Zapata A, et al. Detection of a protein associated with the disease of acute hepatopancreatic necrosis (AHPND) in Litopenaeus vannamei under semi-intensive culture in Ecuador. Rev Inv Vet Perú. 2018;29(1):328-338

16. Sánchez A, Mendoza-Cano F, Enríquez-Espinoza T, et al. Síndrome de mortalidad temprana del camarón, ¿presente en México? Ciencia y Desarrollo; 2014

17. Sirikharin R, Taengchaiyaphum S, Sanguanrut $P$, et al. Characterization and PCR detection of binary, Pir-Like toxins from Vibrioparahaemolyticus isolates that cause acute hepatopancreatic necrosis disease (AHPND) in shrimp. PLOS ONE. 2015;10(5):e0126987.

18. Han J, Tang K, Tran L, et al. Photorhabdus insect related (Pir) toxin $\square$ like genes in a plasmid of Vibrio parahaemolyticus, the causative agent of acute hepatopancreatic necrosis disease (AHPND) of shrimp. Dis Aquat Organ. 2015;113(1):33-40. 
19. Lee C, Chen I, Yang Y, et al. The opportunistic marine pathogen Vibrio parahaemolyticus becomes virulent by acquiring a plasmid that expresses a deadly toxin. Proc Natl Acad Sci U S A. 2015;112(34):10798-10803.

20. Tran L, Nunan L, Redman RM, et al. Determination of the infectious nature of the agent of acute hepatopancreatic necrosis syndrome affecting penaeid shrimp. Dis Aquat Organ. 2013;105(1):45-55.

21. Kondo H, Van PT, Dang LT, et al. Draft genome sequence of nonVibrio parahaemolyticus acute hepatopancreatic necrosis disease strain KC13.17.5, isolated from diseased shrimp in Vietnam. Genome Announc. 2015;3(5):e000978-15.

22. Liu L, Xiao J, Zhang M, et al. A Vibrio owensii strain as the causative agent of AHPND in cultured shrimp, Litopenaeus vannamei. J Invertebr Pathol. 2018;153:156-164.
23. Durán-Avelar M, Vázquez-Reyes A, González-Mercado AL, et al. pirA- and pirB-like gene identification in Micrococcus luteus strains in Mexico. J Fish Dis. 2018;41(11):1667-1673.

24. Varela A, Peña N, Aranguren LF. Acute hepatopancreatic necrosis: a review of the disease in Penaeus vannamei. Rev Agron Mesoam. 2017;28(3):735-745.

25. Varela A, Peña N. Histopatología diferencial de tres enfermedades bacterianas que afectan el hepatopáncreas de camarones peneidos. Rev Agron Mesoam. 2016;27(1):73-80.

26. Varela A. Pathologies of the hepatopancreas on marine shrimp cultivated in America and its differential diagnosis by histopathology. Rev Aquatic. 2018;50:13-30. 